\title{
Prevención secundaria de la nefrolitiasis: eficacia del aumento de la ingesta de líquidos, citratos, alopurinol y tiazidas
}

The effectiveness of increased fluid intake, allopurinol, thiazide and citrate in the secondary prevention of nephrolithiasis

\section{Objetivos}

Realizar una revisión sistemática para evaluar los riesgos y beneficios de distintos tratamientos, tanto farmacológicos como dietarios, en la prevención secundaria de nefrolitiasis.

\section{Fuente de Datos}

MEDLINE, biblioteca Cochrane, Google Académico, clinicaltrials.gov, y Web of Science. Listas de referencia de ensayos clínicos aleatorizados y revisiones sistemáticas, además de artículos sugeridos por expertos.

\section{Selección de datos}

Ensayos clínicos aleatorizados en inglés, que incluían tratamiento farmacológico o tratamiento dietario, para la prevención de recurrencias de nefrolitiasis. Los resultados evaluados eran clínicos, radiográficos o una combinación de ambos, agregando efectos adversos y adherencia. Los participantes eran individuos mayores de 18 años, que hubieran presentado uno a más episodios de nefrolitiasis. El grupo tratante se comparaba con place-
Fink HA y col. Ann Intern Med. 2013;158(7):535-43.

\section{Extracción de datos}

Los datos fueron extraídos por dos revisores independientes, quienes calificaron los trabajos utilizando criterios de calidad y fuerza de evidencia pre-especificados.

\section{Resultados principales}

Se resumen en la tabla 1. Los resultados de las intervenciones dietarias resultaron discordantes por las co-intervenciones del grupo tratante y las distintas intervenciones del grupo control. La evidencia sobre si el tipo de cálculo predice la eficacia del tratamiento en la reducción de la nefrolitiasis es limitada, al igual que las mediciones bioquímicas basales, tanto urinarias como sanguíneas. Si bien la hiperuricosuria y la hiperuricemia parecen predecir la eficacia del tratamiento con alopurinol, en ensayos con citrato y tiazidas que incluían algunos de estos pacientes, también se observó una reducción. Al no haber ensayos comparativos entre el alopurinol y las tiazidas o citratos en este tipo de pacientes no se pueden sacar conclusiones.

Tabla 1: impacto de diferentes estrategias en la prevención secundaria de nefrolitiasis.

\begin{tabular}{|c|c|c|c|c|}
\hline \multicolumn{2}{|c|}{ Intervención } & Resultado evaluado & Riesgo relativo & Diferencia en abandono o efectos adversos \\
\hline \multirow{2}{*}{\multicolumn{2}{|c|}{$\begin{array}{l}\text { Aumento de la ingesta } \\
\text { de líquidos }\end{array}$}} & Compuesto & $0,45(0,24$ a 0,84$)$ & \multirow[t]{2}{*}{ No } \\
\hline & & Radiográfico & $0,15(0,02$ a 1,07$)$ & \\
\hline \multicolumn{2}{|c|}{ Reducción de la ingesta de gaseosas } & Clínico & $0,83(0,71$ a 0,98$)$ & No \\
\hline \multirow{2}{*}{$\begin{array}{l}\text { Dietas } \\
\text { multicomponente }\end{array}$} & a & Compuesto & $0,52(0,29$ a 0,95$)$ & Menor en grupo intervención \\
\hline & b & Compuesto & $5,58(1,39$ a 24,92$)$ & \\
\hline \multicolumn{2}{|l|}{ Alopurinol } & Compuesto & $0,59(0,42$ a 0,84$)$ & Menor en alopurinol \\
\hline \multicolumn{2}{|l|}{ Tiazidas } & Compuesto & $0,52(0,39$ a 0,69$)$ & Mayor en tiazidas \\
\hline \multicolumn{2}{|l|}{ Citrato } & Compuesto & $0,25(0,14$ a 0,44$)$ & Mayor en citrato \\
\hline \multicolumn{2}{|c|}{ Ácido acetohidroxámico } & Clínico e imágenes & No significativo & Mayor en grupo intervención \\
\hline
\end{tabular}

Resultado compuesto: clínico + imágenes. Dieta a) baja en proteínas y sodio, y normal a rica en calcio vs baja en calcio. Dieta b) baja en proteínas animales y rica en fibras vs dieta control.

\section{Conclusiones}

En pacientes con al menos un episodio de nefrolitiasis el incremento de ingesta de líquidos reduce el riesgo de recurrencia. En pacientes con múltiples episodios de nefrolitiasis cálcica el agregado de tiazidas, citra-

to o alopurinol produjo una reducción adicional.

\section{Comentario}

La prevalencia de litiasis renal es del $13 \%$ en hombres y $7 \%$ en mujeres ${ }^{1,2}$ Sin ningún tratamiento específico, la recurrencia a los cinco años se da entre el $35 \%$ y el $50 \%$ de los casos ${ }^{3}$. Es sabido que muchos de los pacientes con nefrolitiasis recurrentes tienen trastomos metabólicos de base que aumenta su predisposición $n^{4.5}$. Por lo tanto, en la práctica clínica se suelen solicitar dos muestras de orina de 24 horas, cada una con su correspondiente muestra de sangre, donde se miden parámetros bioquímicos. También se recomienda determinar la composición de los cálculos. Sin embargo, no existen evidencias claras en el impacto que tiene cada tratamiento en relación a cada trastomo, ni en el tipo de cálculo o características del paciente. Con este trabajo, tampoco se puede concluir claramente ninguna relación entre estas variantes y el tratamiento. En primer lugar, por los pocos ensayos sobre tratamientos comparativos, pudiendo existir sesgo de publicación. Además, hay que agregar la calidad y el grado de evidencia de los ensayos clínicos,
Fuente de financiamiento y conflictos de interés de los autores: Agency for Healthcare Research and Quality (AHRQ).

Burdisso Natividad [ Servicio de Medicina Familiar y Comunitaria del Hospital Italiano de Buenos Aires; natividad.burdisso@hospitalitaliano.org.ar ]

Burdisso N. Prevención secundaria de la nefrolitiasis: eficacia del aumento de la ingesta de líquidos, citratos, alopurinol y tiazidas. Evid Act Pract Ambul. Ene-Mar 2014;17(1):8. Comentado de: Fink HA, Wilt TJ, Eidman KE, et al. Medical management to prevent recurrent nephrolithiasis in adults: a systematic review for an American College of Physicians Clinical Guideline. Ann Intern Med. 2013;158(7):535-43. PMID: 23546565.

Referencias

1. Pearle MS et al. Urologic diseases in America project: urolithiasis. J Urol. 2005:173:848-57.

2. Stamatelou KK, et al. Time trends in reported prevalence of kidney stones in the United States: 1976-1994. Kidney Int. 2003;63:1817-23.

3. Uribarri J, et al. The first kidney stone. Ann Intern Med. 1989;111:1006-9.

4. Wagner CA, Mohebbi N. Urinary pH and stone formation. J Nephrol. 2010;23 Suppl 16:S165-9.

5. Levy FL, Adams-Huet B, Pak CY. Ambulatory evaluation of nephrolithiasis: an update of a 1980 protocol. Am J Med. 1995;98:50-9. 